Research, part of a Special Feature on Catastrophic Thresholds, Perspectives, Definitions, and Applications

\title{
Quantification of the Ecological Resilience of Drylands Using Digital Remote Sensing
}

\author{
$\underline{\text { Robert A. Washington-Allen }}^{1}, \underline{R . D . R a m s e y}^{2}, \underline{\text { Neil E. West }}^{2}$, and Brien E. Norton $^{3}$
}

\begin{abstract}
Drylands cover $41 \%$ of the terrestrial surface and support $>36 \%$ of the world's population. However, the magnitude of dryland degradation is unknown at regional and global spatial scales and at 15-30-yr temporal scales. Historical archives of $>30 \mathrm{yr}$ of Landsat satellite imagery exist and allow local to global monitoring and assessment of a landscape's natural resources in response to climatic events and human activities. Vegetation indices (VIs), i.e., proxies of vegetation characteristics such as phytomass, can be derived from the spectral properties of Landsat imagery. A dynamical systems analysis method called mean-variance analysis can be used to describe and quantify dynamic regimes of VI response to disturbance using characteristics of ecological resilience, particularly amplitude and malleability, from a change detection perspective. Amplitude is the magnitude of response of a VI to a disturbance; malleability is the degree of recovery of a resource after a disturbance. Spatially aggregate and spatially explicit (image) differencing are methods whereby a VI image or statistic from one time period is subtracted from a VI image or statistic from another time period. To illustrate this method, we used a time series of Landsat imagery from 1972 to 1987 to measure the response of vegetation communities that are managed by subsistence agropastoral communities to the severe 1982-1984 El Niño-induced drought on the Bolivian Altiplano. We found that the entire landscape had decreased vegetation cover, increased variance (diagnostic of a regime shift), and thus, increased susceptibility to soil erosion during the drought. The wet meadow vegetation cover class had the lowest amplitude and thus the most resilience relative to other vegetation cover classes. This response identified the wet meadow as a key resource, as well as a harbinger of climate change for agropastoral communities in areas where drought is an endemic stressor.
\end{abstract}

Key Words: change detection; ecological resilience; El Niño Southern Oscillation; environmental monitoring, image differencing, Landsat, remote sensing

\section{INTRODUCTION}

Assessments of livestock development projects in the 1980s and 1990s concluded that the failure of these projects in developing countries was caused by an assumption of stable or equilibrium conditions in drylands and a failure to monitor the ecological and socioeconomic resilience of existing systems, particularly during drought (Ellis and Swift 1988, Moris 1988, Buttolph and Coppock 2004). Current environmental monitoring and assessment of drylands has also failed to determine the degree of land degradation at regional to global spatial scales (H. John Heinz III Center for Science, Economics, and the Environment 2002, Millennium Ecosystem Assessment 2005). For example, global assessments that were conducted between 1981 and 2001 estimated that $10-70 \%$ of drylands were degraded in terms of reduced vegetation canopy cover and accelerated soil erosion (Oldeman et al. 1991, Dregne and Chou 1992, Lepers et al. 2005, Millennium Ecosystem Assessment 2005). This discrepancy in the range of estimates has been attributed to multiple definitions of drylands (Lund 2007) and the failure to conduct monitoring at the appropriate spatial and temporal scales (West 2003a, b, Washington-Allen et al. 2006, Zimmermann et al. 2007). For example, drylands are usually monitored using vegetation field survey techniques that use a specific sampling design to reduce spatial variability; however, the costs to implement such a design at regional to global scales are temporally

${ }^{1}$ Texas A\&M University, ${ }^{2}$ Utah State University, ${ }^{3}$ Centre for the Management of Arid Environments 
and spatially prohibitive using the required repeated sampling. Another major problem in dryland monitoring is the separation of effects due to climatic events such as drought from the effects of anthropogenic activities such as commercial livestock grazing. The El Niño Southern Oscillation (ENSO) is a major climatic event that globally influences soil dynamics and the abundance, community structure, and species and genetic diversity of dryland flora and fauna. The ENSO globally induces either severe floods or intense droughts in drylands for a period of $\geq 12-18$ months (Glantz 2001) and has a return interval of 2-10 yr (Glantz 2001, Holmgren and Scheffer 2001, Holmgren et al. 2001, 2006). In addition, global climate change is predicted to increase the frequency and intensity of droughts that occur under warming temperatures (Breshears et al. 2005). Repeated and severe droughts have resulted in mass die-offs of vegetation in semi-arid and arid drylands (Breshears et al. 2005). Consequently, dryland monitoring requires data, methods, and technology that span the 15-30 yr that are required to replicate, separate, and integrate the effects of land management activities from the effects of major climatic events (Washington-Allen et al. 2006). A technology that meets these temporal and spatial scale requirements and from which ecological indicators of dryland degradation can be derived is satellite remote sensing, particularly the $\geq 30-36$ yr Advanced Very High Resolution Radiometer (AVHRR) and the Landsat program's Multispectral Scanner, Thematic Mapper (TM), and Enhanced TM (Graetz 1987, Tueller 1989, Goward and Masek 2001, Hunt et al. 2003, Washington-Allen et al. 2006). Both sensors collect data at a global scale: the AVHRR collects data twice daily at a pixel spatial resolution of $1-9 \mathrm{~km}^{2}$; Landsat collects data every 14-16 days at a relatively finer spatial resolution ranging from 225 to $14,400 \mathrm{~m}^{2}$.

Dryland degradation can be defined as a decrease in plant cover, density, productivity, or some other plant parameter or measure of vegetation attributes (Washington-Allen et al. 2004a, b, 2006). Indicators that are diagnostic of these attributes can be derived from the spectral and textural characteristics of Landsat satellite imagery (Tueller 1989, Quattrochi and Pelletier 1991). For example, the spectral characteristics of Landsat data (i.e., 450-2350 nm or from blue to mid-infrared, including thermal infrared) in relation to the spectral reflectance characteristics of surface features allows the development of biophysical models such as the normalized difference vegetation index (NDVI), which relies on the difference in the percent reflectance of incident near infrared (NIR) and red (R) energy from leaf tissue. The NDVI is calculated as

$$
\mathrm{NDVI}=\mathrm{NIR}-\mathrm{R} / \mathrm{NIR}+\mathrm{R}
$$

The NDVI is significantly correlated with vegetation attributes that are commonly measured in the field, including the leaf area index, plant cover, and phytomass (Sellers 1985). If a time series of multiple NDVI scenes is available, then spatiotemporal maps can be generated to detect trends across a landscape (Washington-Allen et al. 2004a, $b)$. The time series of daily NDVI scenes that are available from AVHRR can be summed on an annual basis ( $\sum$ NDVI) to give a correlate of annual aboveground net primary productivity (ANPP; Prince 1991). If an annual or interannual time series of NDVI or NDVI-derived ANPP images is available, then spatio-temporal maps of the three basic trends that are important to land managers, $i$. e., decreasing, increasing, or stable trends, can be derived using multivariate analysis (Eastman and McKendry 1991, Washington-Allen et al. 2004a). Alternatively, a change-detection method called image differencing can be performed to provide a spatially explicit visualization of the difference in vegetation response between two or more time periods at the pixel level (Washington-Allen et al. 1998). Both spatially aggregate methods (e.g., descriptive statistics such as the mean) and spatially explicit methods (e.g., image differencing) can be used to measure ecological resilience (Wessels et al. 2004, 2007). Ecological resilience is defined as the degree, manner, and pace of the restoration of vegetation attributes after a disturbance (Westman 1985). Ecological resilience and its characteristics (Table 1) have been quantified statistically in both ecosystem simulations (O'Neill 1976, Westman and O'Leary 1986), plant community field studies (Westman and O'Leary 1986), and regional analyses of land degradation (Wessels et al. 2004, 2007).

O'Neill (1976) simulated energy flow through a three-compartment (autotrophs, heterotrophs, and detrivores) model for six different biomes to test their ability to recover from a $10 \%$ reduction in plant biomass over a 25 -yr period. A recovery index, i.e., 
Table 1. Characteristics of ecological resilience and examples of their application (Orians 1975, Westman 1985, Westman and O'Leary 1986).

\begin{tabular}{|c|c|c|}
\hline Characteristic & Definition & Example \\
\hline Inertia & The magnitude of resistance to change & $\begin{array}{l}\text { The grazing pressure required to affect change in } \\
\text { percent plant cover }\end{array}$ \\
\hline Elasticity & $\begin{array}{l}\text { The period of restoration to a reference } \\
\text { condition following disturbance }\end{array}$ & The time required to return to $70 \%$ plant cover \\
\hline Amplitude & $\begin{array}{l}\text { The threshold or magnitude of change as a result } \\
\text { of a disturbance from which a system will return } \\
\text { to a reference state }\end{array}$ & $\begin{array}{l}\text { The amount of reduction in plant cover from } \\
\text { initial conditions in concert with a drought }\end{array}$ \\
\hline Hysteresis & $\begin{array}{l}\text { The degree to which the path of restoration is an } \\
\text { exact reversal of the path of degradation }\end{array}$ & $\begin{array}{l}\text { The degree to which the recovery of plant cover } \\
\text { is not an exact reversal of the pattern of decline }\end{array}$ \\
\hline Malleability & $\begin{array}{l}\text { The degree to which the state established after a } \\
\text { disturbance differs from the original state }\end{array}$ & $\begin{array}{l}\text { The percent plant cover before drought } \\
\text { compared to that after drought }\end{array}$ \\
\hline Damping & $\begin{array}{l}\text { The pattern of oscillations in an ecosystem } \\
\text { component following disturbance }\end{array}$ & $\begin{array}{l}\text { Changes in percent vegetation cover following } \\
\text { disturbance }\end{array}$ \\
\hline
\end{tabular}

a measure of the amount of deviation from a reference equilibrium value or initial state after a disturbance (a measure of malleability), was computed for each year over the 25 -yr period. The mean malleability of each biome for this period was interpreted to indicate which biomes were least and most resistant to disturbance (O’Neill 1976).

Westman and O'Leary (1986) developed four measures of ecological resilience: elasticity, i.e., the rate of recovery from a disturbance; amplitude, i.e., the threshold beyond which recovery to a previous reference state no longer occurs; malleability; and damping, i.e., the extent and duration of an ecosystem parameter following disturbance. These were used to estimate the responses of various plant functional types within a coastal sage scrub plant community at 5-6 yr after fire using field data and for $200 \mathrm{yr}$ after fire using a simulation model.

Wessels et al. $(2004,2007)$ used an interannual time series of AVHRR- and Moderate Resolution Imaging Spectroradiometer (MODIS)-derived NDVI (or ANPP) from 1985 to 2005 to examine the resilience of a landscape in northeastern South Africa that had been subject to both overpopulation and apparent overgrazing by the forced settlement of pastoralists into "homelands" during the apartheid era from 1910 to 1994. A spatially aggregated approach was used in which the mean annual $\sum$ NDVI for the period of 1985-2005 was compared between nondegraded benchmark areas and degraded areas within the homelands as

$$
\mathrm{RDI} \text { or PD }=\frac{\text { nondegraded } \sum \text { NDVI }- \text { degraded } \sum \text { NDVI }}{\text { nondegraded } \sum \text { NDVI }} \times 100
$$

where RDI is the relative degradation index or the percent difference (PD) between the mean NDVIs of nondegraded and degraded sites (Wessels et al. 2004, 2007). Wessels et al. (2004, 2007) found that these paired sites were significantly different from each other and that degraded sites had significantly lower mean annual NDVI than did nondegraded sites. Also, there was no indication of recovery (malleability) of degraded sites toward the mean conditions of nondegraded sites from the end of the apartheid era in 1994 to 2005 (Wessels et al. 2004, 2007). This provided evidence in support of the hypothesis that the observed migrations of former rural homeland populations to jobs in major urban 
centers such as Johannesburg and Durban is due in part to environmental degradation of the homelands. However, at the coarse resolution of MODIS (0.25 $\left.\mathrm{km}^{2}\right)$ and AVHRR $\left(1 \mathrm{~km}^{2}\right)$, it was observed that finer-scale phenomena at the community and species levels were masked or averaged out (Wessels et al. 2007). A number of scaling studies in drylands suggest characteristic length scales for vegetation and bare soil patches of approximately 1-100 m; these scales are probably not amenable to analysis using spatially coarse-resolution sensors such as MODIS or AVHRR (Hudak and Wessman 1998, Rietkerk et al. 2004). To account for this disparity, Wessels et al. (2007) suggested a staged remote sensing approach to monitoring at regional and national scales in which both coarse-resolution sensors such as MODIS are used in conjunction with relatively finer-resolution data sets such as Landsat, the data set of choice in our analysis.

Our aim was to follow Moris' (1988) recommendation by quantifying the ecological resilience of the response of a Bolivian agropastoral community's drylands to multiyear droughts, particularly the 1982-1984 ENSO-induced drought event, using a limited 16-yr historical time series of Landsat satellite imagery from 1972 to 1987. Specifically, our objectives were: (1) to demonstrate that mean-variance analysis, a form of graphical dynamical systems analysis, can provide insight into the ecosystem dynamics of various dryland plant communities in response to drought; (2) to demonstrate that the change detection technique of image differencing of satellite imagery is a complementary technique to mean-variance analysis and can provide spatially explicit information on the location(s) of a landscape's response to disturbances; (3) to compare the ecological resilience, particularly the amplitude and malleability, of different plant communities in response to a major drought; and (4) to demonstrate the utility of using remote sensing data to characterize ecological resilience in response to repeated drought disturbances. We defined disturbance as a discrete event in time, e.g., a drought or fire, that significantly reduces the abundance of a natural resource, e.g., vegetation or soil nutrients (Connell and Sousa 1983).

The late Dr. James E. Ellis, formerly of the Natural Resources and Ecology Laboratory at Colorado State University, Colorado, USA, has suggested that because of the long grazing history of llama and alpaca herds on the Bolivian Altiplano, the vegetation response in terms of species composition and biomass or cover should be highly resilient and relatively stable (Browman 1974, Ellis 1992). However, Painter (1992) observed that extensive crop failures occurred in the rural areas of central and southern Bolivia during the 1982-1984 ENSOinduced drought event and that this resulted in the migration of many households into major urban centers. Consequently, Painter (1992) hypothesized that these migrations were due to increased degradation of the land base by droughts and agricultural land-use practices, particularly grazing and cropping. This suggests that this area of the Altiplano has lost resilience in the face of multiple droughts.

\section{METHODS}

\section{Study area}

The 6604-ha study site canton San José Llanga (for a description, see Washington-Allen et al. 1998) is located at $17^{\circ} 20^{\prime}-17^{\circ} 30^{\prime} \mathrm{S}, 67^{\circ} 5^{\prime}-68^{\circ} \mathrm{W}$ within the Northern Altiplano physiographic province, approximately $120 \mathrm{~km}$ south of La Paz, the capital of Bolivia (Fig. 1). The community is $>500 \mathrm{yr}$ old and comprises six villages. The local economy is predominantly subsistence and depends primarily on ecologically linked agricultural activities, i.e., potato production, and pastoral activities, i.e., sheep meat, wool, and manure production, and is thus an agropastoral ecosystem (McCorkle 1992). These activities are supplemented by cash income from limited dairy, fuel-wood, and manure enterprises (Nolan 1992, Norton 1994).

The elevation of the study site is $3725-3786 \mathrm{~m}$ above sea level, and slopes range from $0^{\circ}$ to $7^{\circ}$. The site is a salt playa (salar) of concentrated saline/ sodic salts that compose one-third of the landscape. These salts were precipitated from glacial lakes that evaporated some 10,000 yr ago. Soil textures range from silt to clay in all land-use types, except in the agricultural and village areas, where aeolian deposition of coarse- to fine-textured sand dunes of varying depths occurs over a clay-textured A horizon. The average depth to groundwater is approximately $0.5 \mathrm{~m}$ from the surface. The groundwater has varying levels of salinity, with electrical conductivity ranging from 0.8 to $25 \mathrm{mS} /$ $\mathrm{cm}$. Flooding during the wet season results in alluvial deposition in low-lying areas. The mean annual precipitation is $402 \mathrm{~mm}$, and the mean annual 
Fig. 1. The study site, San Jose Llanga, is located in the northern Altiplano of Bolivia, $120 \mathrm{~km}$ south of the capital city of La Paz. The vegetation cover map is adapted from Norton (1992) and WashingtonAllen et al. (1998).

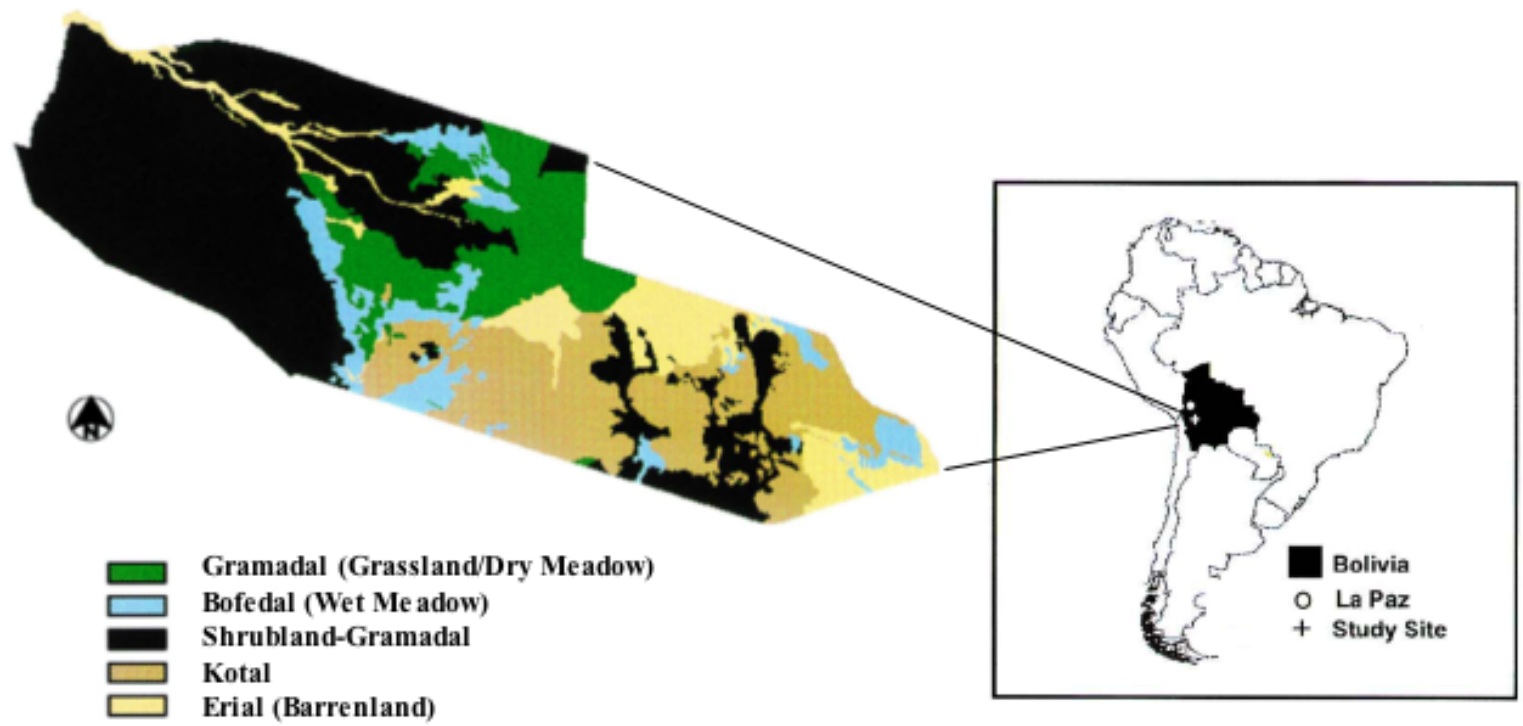

temperature is $10.4^{\circ} \mathrm{C}$. Frosts occur between March and June with $>80 \%$ frequency. Like most areas in the Andes, there are marked wet and dry seasons; the former occurs from November to April (Johnson 1976). Historical climatic data from a weather station located near the study site indicate that droughts of $25 \%$ below mean annual precipitation occur $17 \%$ of the time and droughts of at least $50 \%$ below mean annual precipitation occur $6 \%$ of the time within the study area. The coefficient of variation for historical annual precipitation is $31 \%$, which suggests that this ecosystem exhibits nonequilibrial plant-herbivore dynamics in which vegetation dynamics are more closely coupled to water availability than to herbivory (Ellis 1992, Buttolph and Coppock 2004).

Field studies indicate that the plant community is represented by five land-cover classes (Fig. 1). (1) Shrubland-grassland is dominated by the shrub Parastrephia lepidophylla, with Festuca dolichophylla as an associated tall bunch-grass, on sandy-textured alluvial soils. (2) Bofedal, or wet meadow, is dominated by Calamagrostis curvula and Carex 
spp., with clay soils and low-salinity groundwater at or near the surface for most of the year. (3) Gramadal, or grassland/dry meadow, is dominated by the halophytic shortgrass Distichlis humilis and Hordeum muticum and the tall bunchgrass Stipa $i c h u$. (4) Barren land, or erial, is associated with small areas of salt playa, intermittent flooding, and sparse, low-density, spotted clumps of Anthobryum triandrum, a halophytic cushion plant or half-shrub that belongs to the Primulaceae and is generally associated with soils that contain $\pm 4 \mathrm{~g} / \mathrm{kg}$ soluble salts (Salm and Gehler 1987). (5) Kotal is the local term for sites that are dominated by a high-density spotty to mat-like cover of Anthobryum triandrum.

\section{Image processing}

The image data set consisted of a 16-yr archived data set of one Thematic Mapper (TM) and three Landsat Multispectral Scanner (MSS) scenes from 1972 to 1987 (Table 2). The processing of these data has been described by Washington-Allen et al. (1998). The criteria for data acquisition were: lowcost acquisition of scenes that were representative of the dry season, $\leq 10 \%$ cloud cover, anniversary dates between scenes, and coincidence with the 1982-1984 El Niño Southern Oscillation (ENSO) drought event discussed by Painter (1992). A lowcost time series of scenes that included the 19971998 ENSO drought event scenes was sought from free data archives, particularly the University of Maryland's Global Land Cover Facility (http://esip. umiacs.umd.edu/index.shtml). However, only one 2001 scene fit the acquisition criteria explained above, and without the intervening dates between 1987 and 2001, no new information on spatial effects were provided beyond those gained from the study of the 1982-1984 ENSO event. Consequently, the methodology presented here has the added advantage of being quite useful when only limited imagery time series are available.

Dry season data were acquired to monitor the more persistent vegetation cover of perennials and to avoid the short-term variation from annuals and other sources of ephemeral vegetation cover. However, the 31 October 1972 MSS scene from the wet season was used because it was the earliest representation available for initial site conditions. Image processing was conducted, including radiometric correction, image-to-image registration, time series standardization (conversion to exoatmospheric reflectance), and atmospheric correction
(Washington-Allen et al. 1998). We addressed the spectral compatibility between TM and MSS data by direct substitution of TM bands 3 (red, R) and 4 (near infrared, NIR) for MSS bands $2(\mathrm{R})$ and 4 (NIR; Crist and Cicone 1984, Suits et al. 1988). The standardized time series was then converted to a transformed normalized difference vegetation index (TNDVI), which has a better signal-to-noise ratio in drylands than the NDVI (Deering et al. 1975, Perry and Lautenschlager 1984) and provides further atmospheric correction of the satellite data (Pickup 1990). The TNDVI is calculated as

$$
\text { TNDVI }=50(\mathrm{NDVI}+1)
$$

Image processing occurred in an older command line version of the Earth Resources Data Analysis System, ERDAS 7.5 (ERDAS Imagine 1990), which produced nonfloating point results. Consequently, for improved visualization, the TNDVI was scaled between 0 and 100, with the actual data-set values scaled between 33 and 80 .

\section{Mean-variance plots}

Graphical analysis of a dynamical system uses phase diagrams or portraits that describe the motion or trajectory of states through time (Morse et al. 2000). Pickup and Foran (1987) developed a special case of this analysis, called mean-variance analysis, to characterize the spatiotemporal behavior of a remotely sensed vegetation index (VI). A meanvariance portrait can be used to describe the seasonal and interannual response of vegetation to climate and disturbance (Washington-Allen et al. 2003, Zimmermann et al. 2007). Fig. 2 illustrates the hypothetical trajectory of the VI of an agricultural crop that has been bred to minimize variability. We used field measurements of percent vegetation cover to calibrate the TNDVI. Physically, the mean of a VI may correlate with vegetation cover, density, or standing crop (Sellers 1985). The 1987 TNDVI values for five vegetation classes were compared to those in 1992, and a consistent relationship was found ( $r=0.93, n=5$; Washington-Allen et al. 1998, Nelson Massy unpublished data). Additionally, Washington-Allen et al. (1998) found that field measurements of percent vegetation cover for 14 vegetation types in 1992 were correlated with TNDVI values in $1986(r=0.76)$. This relationship 
Table 2. Characteristics of the Landsat satellite data used.

\begin{tabular}{cccccc}
\hline \hline $\begin{array}{c}\text { Image date } \\
(\text { dd-mm-yyy) }\end{array}$ & Sun elevation angle & Landsat number & Scanner $\dagger$ & Season & $\begin{array}{c}\text { Root mean square } \\
\text { error }\end{array}$ \\
\hline $31-10-1972$ & 32 & 1 & MSS & Wet & 0.49489 \\
$08-07-1984$ & 35 & 5 & TM & Dry & 0.46038 \\
$15-08-1986$ & 39 & 5 & MSS & Dry & 0.45213 \\
$02-08-1987$ & 37 & 5 & MSS & Dry & 0.46662 \\
\hline
\end{tabular}

†TM, Thematic Mapper; MSS, Multispectral Scanner.

was used to approximate a $20 \%$ cover line (mean TNDVI $=30$ ) to indicate the amount of cover at which soil background noise may dominate the VI vegetation signal (Ringrose and Matheson 1987). This line allows the interpretation of site condition and trajectory with regard to percent vegetation cover and, by extension, bare ground as a surrogate for soil erosion.

The variance of the TNDVI is representative of the degree of landscape heterogeneity or balance between bare soil and vegetation patches (Pickup and Foran 1987, Washington-Allen et al. 2003). Consequently, the variance provides an indirect measure of a site's susceptibility to soil erosion; if a normal distribution is assumed, large TNDVI variance is indicative of a high likelihood that pixels with low TNDVI values at the distribution's tails consist of either reduced vegetation or bare soil cover (Fig. 2). The portrait is divided into four sectors that are delineated by the grand mean and mean variance of a landscape's VI time series (Fig. 2 ). Each sector describes the state of a landscape's trajectory. Specifically, sector 1 (low mean and low variance) can be considered the most degraded state of this landscape; sector 2 (low mean and high variance) indicates that a higher proportion of the landscape tends toward bare ground and thus high susceptibility to erosion; sector 3 (high mean and high variance) means that a higher proportion of the landscape has vegetation cover, but depending on skewness, a small proportion of the landscape is susceptible to erosion; and sector 4 (high mean and low variance) indicates the most ideal and stable condition for this VI landscape (Fig. 2). We constructed mean-variance plots for the wholelandscape response, as well as for each individual vegetation cover class.

\section{Ecological resilience}

Mean-variance plots can be quantified further in terms of the characteristics of ecological resilience (Table 1). We focused on the amplitude, malleability, and damping response of the agropastoral landscape. The significance of change implies statistical boundaries or thresholds, i.e., the points at which the normal range of behavior is exceeded. For our purposes, a significant change is viewed as a departure from initial vegetation conditions represented by the 1972 TNDVI image (the MSS scene in Table 2). The 1972 TNDVI image represents the first year that data were produced by the Landsat series of satellites and thus represents reference conditions for our time series. The chosen reference state determines the standard of evaluation and interpretation of the effects of various disturbances. Reference vegetation conditions can be represented by departures from a TNDVI minimum image. For example, pastoralists tend to manage for drought conditions, and the 1984 TNDVI image represents the 1982-1984 ENSO drought event that was a period of very low TNDVI values (Washington-Allen et al. 1998). Reference vegetation conditions can also be represented by 
Fig. 2. Hypothetical statistical phase portrait of the interannual mean-variance dynamics of an agricultural landscape's vegetation index $(\mathrm{VI}) . \mathrm{T}=$ time.

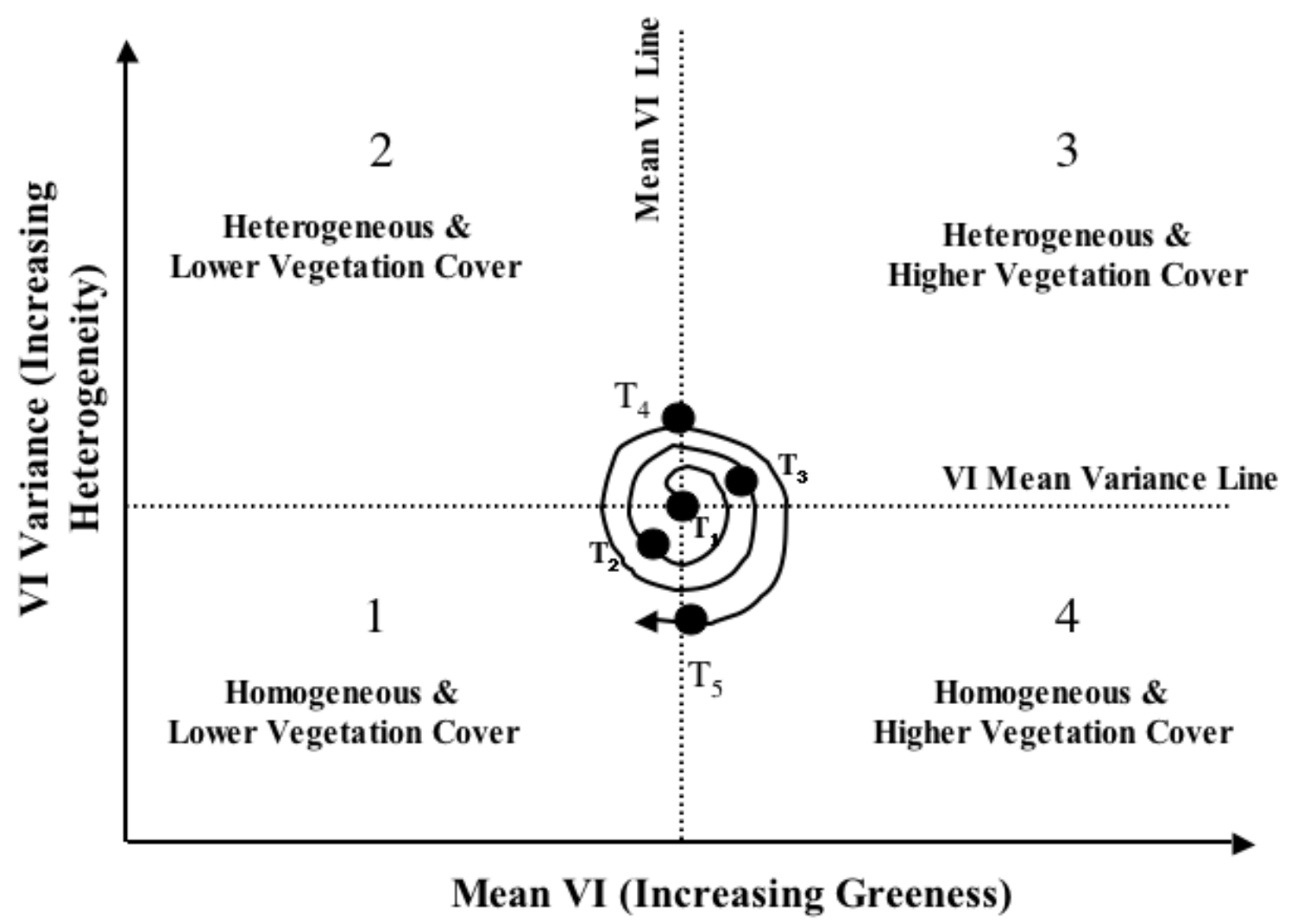

departures from a boundary state such as the $20 \%$ vegetation cover proxy that was established above or maximum or mean VI values (Washington-Allen et al. 2006).

Statistical differencing is a spatially aggregate approach whereby the combined effects of a disturbance at the landscape scale are reported as a single number, i.e., the percentage of pixels affected by the disturbance or the differences of the image means and the image variances at various time periods as derived from mean-variance plots. Image differencing is a form of change detection that allows spatially explicit quantification and visualization of change in a landscape. Here, we report both analyses. Image differencing has the general form (Singh 1989, Jensen 2005)

$$
\Delta B V_{i j k}=B V_{i j k}(2)-B V_{i j k}(1)+c
$$

where $\Delta \mathrm{BV}_{\mathrm{ijk}}$ is the change in each pixel's brightness value (BV) in line number $i$ and column 
number $j$ in a single spectral band $k, \mathrm{BV}_{\mathrm{ijk}}(1)$ is the pixel value on the initial or baseline date 1 , and $B V_{i j k}$ (2) is the pixel value on date 2 (Jensen 2005). We used VI image differencing of the TNDVI, rather than band differencing, in which

$$
\Delta \operatorname{TNDVI}_{\mathrm{ij}}=\operatorname{TNDVI}_{\mathrm{ij}}(2)-\operatorname{TNDVI}_{\mathrm{ij}}(1)+\mathrm{c}
$$

where $\triangle T_{N D V I}$ is the change in each pixel's TNDVI value, TNDVI ${ }_{\mathrm{ii}}(1)$ is the pixel value on the initial date 1 , and $\operatorname{TNDVI}_{\mathrm{ij}}(2)$ is the pixel value on date 2. The $c$ is a constant that accounts for image misregistration errors and allows conservatism about the degree of change that occurs (Singh 1989, Washington-Allen et al. 1998, Jensen 2005). Washington-Allen et al. (1998) conducted six combinations of image differencing with four TNDVI images in which $c$ equaled the mean standard deviation of the six difference images $( \pm 2$ standard deviations of TNDVI).

The amplitude $\left(\Delta \mathrm{TNDVI}_{\mathrm{ijA}}\right.$, where $A$ indicates amplitude) is the magnitude of change after or in concert with a disturbance state $(D)$ from which a system may or may not return compared to a reference state $(R)$, or that in 1972 in our analysis. If the disturbance is such that the system does not recover, then it has exceeded a threshold. The amplitude $\left(\Delta \mathrm{TNDVI}_{\mathrm{ijA}}\right)$ is calculated as

$$
\left|\Delta \operatorname{TNDVI}_{\mathrm{ij \textrm {A }}}\right|=\operatorname{TNDVI}_{\mathrm{ijD}}(1984)-\operatorname{TNDVI}_{\mathrm{ijR}}(1972)=\mathrm{c}(6)
$$

where $\left|\Delta \mathrm{TNDVI}_{\mathrm{ijA}}\right|$ is the absolute value of the difference between the $\operatorname{TNDVI}_{\mathrm{ik}}(1972)$ and TNDVI $_{\mathrm{ik}}(1984)$ disturbance scenes on a pixel-bypixel basis.

Malleability $\left(\Delta \mathrm{TNDVI}_{\mathrm{ijM}}\right.$, where $M$ indicates malleability) is the degree to which subsequent postdisturbance dates differ from the reference state and is a measure of recovery, calculated as $\begin{aligned} \Delta \operatorname{TNDVI}_{\mathrm{ijM}}= & \left|\Delta \operatorname{TNDVI}_{\mathrm{ijA}}\right|-\left(\left\{\operatorname{TNDVI}_{\mathrm{ij}}(1985), \ldots\right.\right. \\ & \left.\left.\operatorname{TNDVI}_{\mathrm{ij}}(\text { date }+1)\right\}-\operatorname{TNDVI}_{\mathrm{ijR}}(1972)\right)(7)\end{aligned}$

Recovery to reference conditions is indicated when $\Delta \mathrm{TNDVI}_{\mathrm{ijM}} \leq 0$.

Damping is a measure of the pace of recovery after a disturbance and/or the amount of landscape affected by a disturbance while moving toward a reference recovery state. The period after the disturbance can be represented by the mean for years after the disturbance or it can be calculated for each subsequent year. We used the means and variances of the 1986 and 1987 TNDVI scenes to represent the period after the severe 1982-1984 ENSO drought. When the calculation is done for the time prior to the disturbance and the $\Delta \mathrm{TNDVI}_{\mathrm{ijM}}$ is subtracted from the result, this is a measure of hysteresis. We do not report hysteresis because we did not have sufficient data to characterize the conditions between 1972 and 1984.

These equations were used to calculate the characteristics of resilience on a pixel-by-pixel basis. However, the mean and mean variance of these characteristics from either a mean-variance portrait or the difference image for each characteristic of resilience (e.g., amplitude, or $\Delta \mathrm{TNDVI}_{\mathrm{A}}$ ) for each date can be used to calculate an aggregate single value, as well as to prepare a map representing the landscape's spatial response to disturbance (e.g., Wessels et al. 2004, 2007).

\section{RESULTS}

\section{Mean-variance analysis}

We plotted mean-variance portraits for the entire landscape and the individual vegetation cover classes (Fig. 3). The effect of the El Niño Southern Oscillation (ENSO) drought on the vegetation response in 1984 is observed in all of the transformed normalized difference vegetation index (TNDVI) mean-variance plots such that the mean TNDVI is low and the TNDVI variance is high and consistently located to the left of the estimated $20 \%$ vegetation cover line. With the exception of bofedal, the vegetation response appears to converge back toward 1972 conditions in 1986 and 1987 (Fig. 3). Not surprisingly, because 
it is not water limited, bofedal had a higher mean TNDVI and a wider range of TNDVI variance compared to the other cover classes (Fig. 3).

\section{Quantification of ecological resilience}

The spatially explicit image difference or amplitude map $\left(\Delta \mathrm{TNDVI}_{\mathrm{ijA}}\right)$ of the study site is the result of Eq. 3, in which the 1984 TNDVI image, which was representative of the 1982-1984 ENSO's disturbance on the landscape, was subtracted from the 1972 reference scene (Fig. 4). Areas of no change were located predominantly in bofedal.

The spatially aggregate measure of the vegetation response of malleability for the agropastoral landscape was -1 for all vegetation classes. Fig. 5 shows the malleability measures for the TNDVI variance (range: -7 to 2 ) for the entire landscape and the individual vegetation cover classes.

Washington-Allen et al. (1998) conducted six change detections for the four TNDVI scenes of the study site, of which two of the cases, i.e., 1984-1986 and 1984-1987, were a measure of damping: the pace of recovery after a disturbance or the amount of landscape affected by a disturbance (the 1984 drought) while moving toward recovery. Damping was measured in 2-yr (1984-1986) and 3-yr (19841987) intervals, in which 99.6 and $99.2 \%$ of the landscape was affected, respectively. Fig. 6 shows the amplitude measures for each statistic of the TNDVI for the entire community and landscape and the individual vegetation cover classes. The TNDVI mean amplitude ranged from 9 to 11 and indicated that all cover classes were affected by the 1984 drought. TNDVI variance amplitude ranged from 0 to 4 (Fig. 6). However, bofedal was the least affected class (amplitude $=9$ ), whereas erial was the most affected (amplitude $=11$ ).

\section{DISCUSSION}

Caution must be used in interpreting the results from this time series because they are limited to available data from 1972 to 1987 and they are interpreted in reference to initial conditions in 1972, drought conditions in 1984, and a field-calibrated $20 \%$ vegetation cover line in mean-variance plots. The 16-yr time series had many gaps in data that were caused by a lack of availability of image data or the failure to meet selection criteria for analysis; thus, the results must be interpreted within the limits of this time series. In addition, vegetation index (VI) difference images or the mean or variance of VIs for a site were used as proxies for change in vegetation cover as an indicator of land degradation (Washington-Allen et al. 2006). Vegetation cover can be related to vegetation productivity, phytomass, and susceptibility to soil erosion. However, caution must be exercised in its interpretation. A VI is an ecosystem measure and does not provide information about changes in species composition. No change may occur in the VI, but changes in species composition within a pixel may occur undetected (Schindler 1987, Washington-Allen et al. 1998). Nonetheless, the use of image differencing to visualize the spatial and temporal changes in the vegetation response of different vegetation classes in mean-variance plots is similar to performing a change vector analysis (Lambin and Strahlers 1994) or using multivariate ordination methods to determine state and threshold changes in plant species composition in response to disturbance (Westoby et al. 1989, Friedel 1991, Van Niel 1995, Washington-Allen et al. 2004a). This similarity can be extended to fitting state changes or cases in which thresholds are exceeded to other indices of land degradation.

The malleability of the TNDVI mean and variance measures the magnitude of recovery to the initial conditions of vegetation cover and spatial heterogeneity (Fig. 2). With respect to the mean TNDVI, all of the classes were approaching recovery. With the exception of bofedal, the TNDVI variance for all classes was close to (TNDVI variance malleability $=-1$ ) or completely recovered to (erial and gramadal TNDVI variance malleability $=0$ ) the reference or initial conditions (1972; Fig. 5). However, bofedal did not return to initial conditions, but appears to have become more spatially homogenous in cover (TNDVI variance malleability $=-7$; Fig. 5).

The bofedal, or wet meadow, vegetation cover class was the most resistant to the effects of severe drought, but its variance was particularly sensitive or highly variable, a behavior that is diagnostic of an impending regime shift and is thus considered to be an early warning signal (O'Neill et al. 1989, Brock and Carpenter 2006). However, this sensitivity to wet and drought periods on the Altiplano is consistent with the hypothesis that wet 
Fig. 3. Mean-variance dynamical portraits of the transformed normalized difference vegetation index (TNDVI) response of San Jose Llanga from 1972 to 1987 at the landscape and vegetation cover class spatial scales. Temporal dynamics are shown with respect to the landscape's mean TNDVI and mean TNDVI variance and a calibrated $20 \%$ vegetation cover line (dotted line). The 1984 vegetation index scene is representative of a severe drought.

Landscape

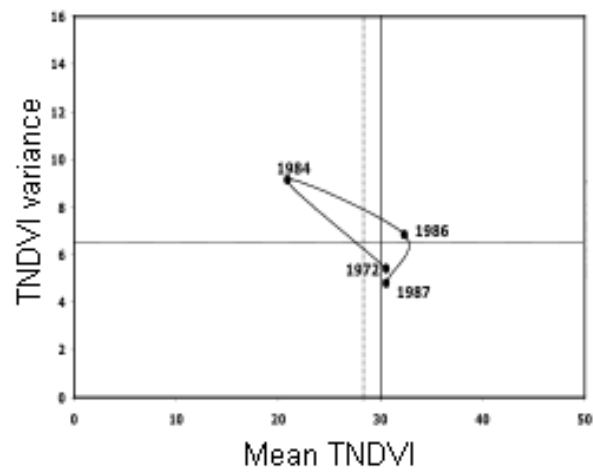

Shrubland-gramadal

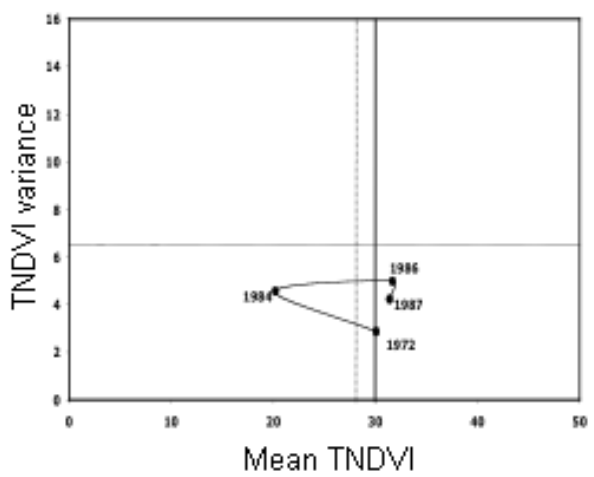

Gramadal

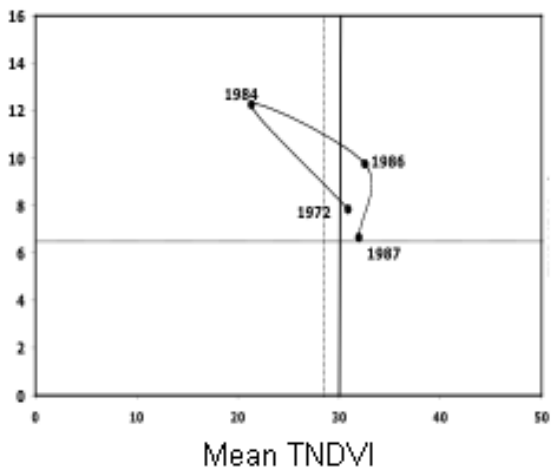

Kotal

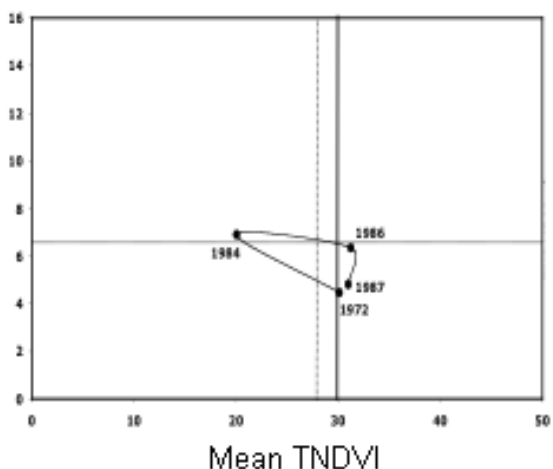

Bofedal

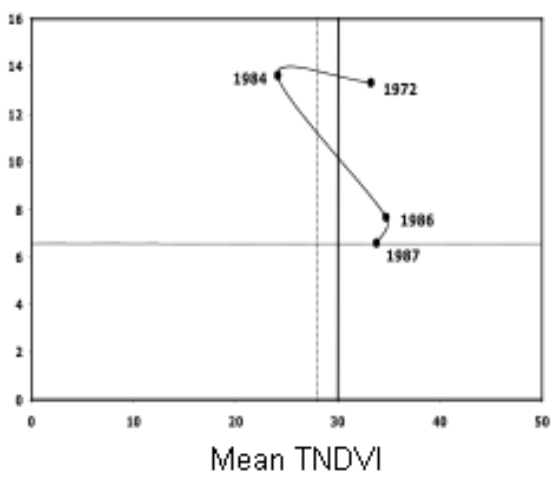

Erial

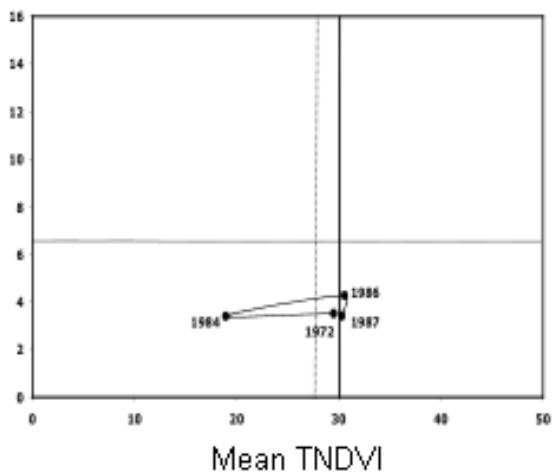

meadows in montane systems are harbingers of global climate change and shifts in biotic communities (Debinski et al. 2006). From the perspective of the agropastoral production system, areas in which the production characteristics change little during a drought may be far more important to the system's maintenance than are areas that experience substantial change (Washington-Allen et al. 1998). This suggests that during drought periods, bofedal is a key resource upon which agropastoral communities depend (Scoones 1991). This finding is consistent with that of Buttolph and Coppock (2004) for bofedal in the northern Altiplano.
With respect to the field calibration of the transformed normalized difference vegetation index (TNDVI) values, the amplitude measure for the TNDVI mean from 1972 to 1987 can be viewed as a surrogate measure of the magnitude of cover loss and susceptibility to erosion for each vegetation cover class in response to drought. The amplitude measures for mean TNDVI indicated a decrease in vegetation response for all vegetation cover classes relative to the 1984 drought. The amplitude measure for TNDVI variance measures the change in spatial distribution or heterogeneity of vegetation cover and bare soil patches. The amplitude measures for TNDVI variance for all vegetation cover sites were 
Fig. 4. Map of the magnitude of change in amplitude after a disturbance. Image differencing is a spatially explicit method to visualize change in a landscape. The subtraction of the vegetation index (VI) reference year (initial conditions in 1972) from the disturbance year (the 1984 drought) is a measure of amplitude. The white areas that did not change are located in bofedal (wet meadow) areas of the study site.

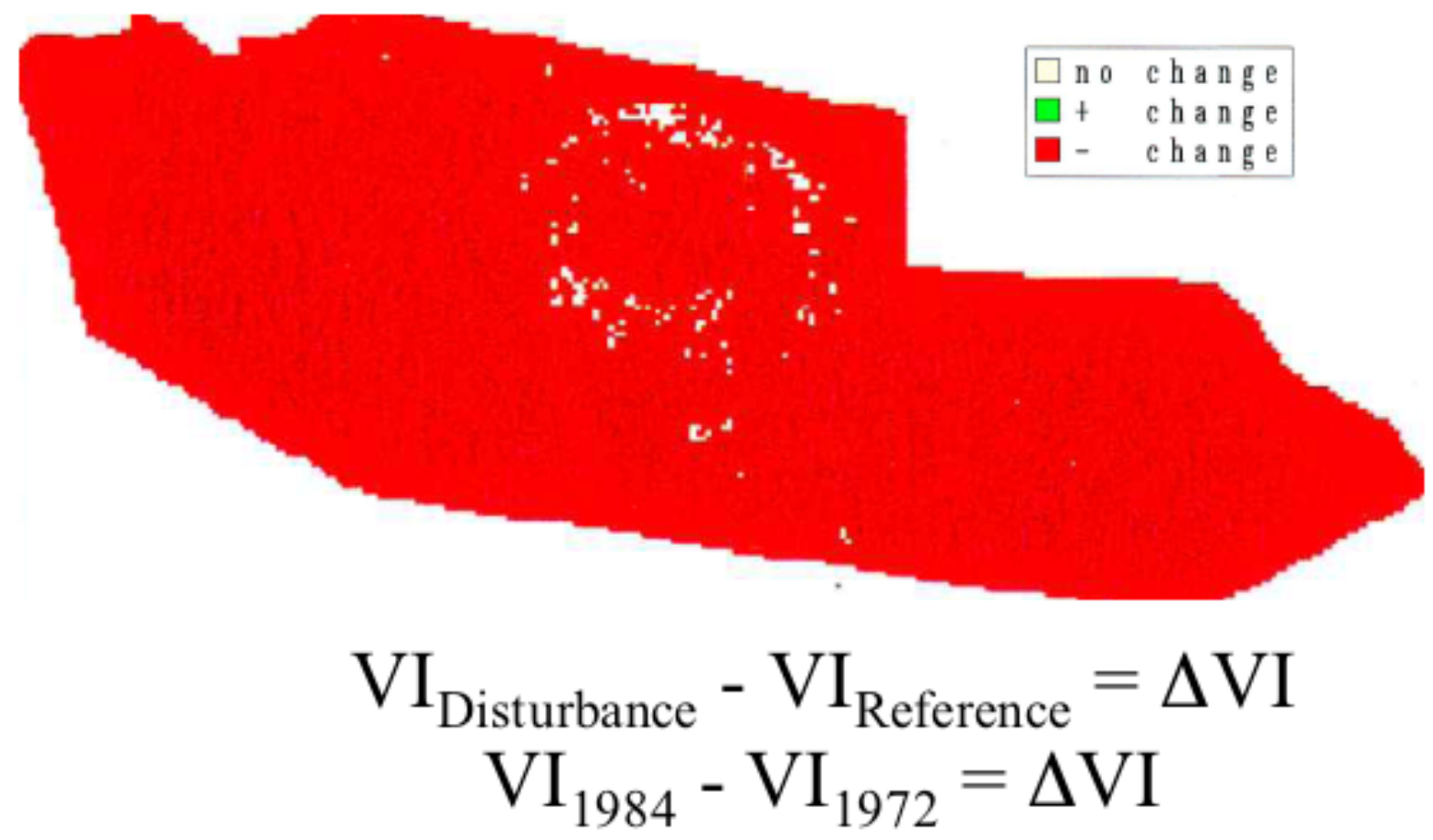

affected by the 1984 drought, but sites for which amplitude TNDVI variance values approached zero were least affected, i.e., their spatial heterogeneity appeared to be the least altered. This included the vegetation cover classes of bofedal, or wet meadow, and erial, or barren land (amplitude of TNDVI variance $=0$; Fig. 6).

The estimation of other characteristics of ecological resilience relative to 1972 initial conditions indicates that inertia (Table 1) is slightly less than $201 \mathrm{~mm}$ of annual rainfall (a drought $50 \%$ below the mean annual precipitation) or the $0 \mathrm{~mm}$ of rain in July of 1984. A better estimate of inertia would come from the measurement of the effects of droughts of various magnitudes. Elasticity (the time to recovery since disturbance; Table 1 ) is estimated at 2 yr, i.e., the period between 1984 and 1986.

\section{CONCLUSION}

Our purpose was to quantify the ecological resilience of the vegetation communities of an agropastoral dryland ecosystem in response to repeated severe droughts using historical archives of satellite imagery. Other than the recent 19971998 El Niño, the global-scale drought and flood effects of the 1982-1984 El Niño Southern Oscillation (ENSO) are considered the most severe 
Fig. 5. Mean-variance portraits are quantified in terms of characteristics of ecological resilience, particularly by malleability, which is the degree of recovery toward initial conditions (in 1972) after a disturbance. Malleability is calculated by subtracting the mean of the transformed normalized difference index (TNDVI) variance for 1986 and 1987 from the mean of the TNDVI variances for 1984, the disturbance (drought) year.

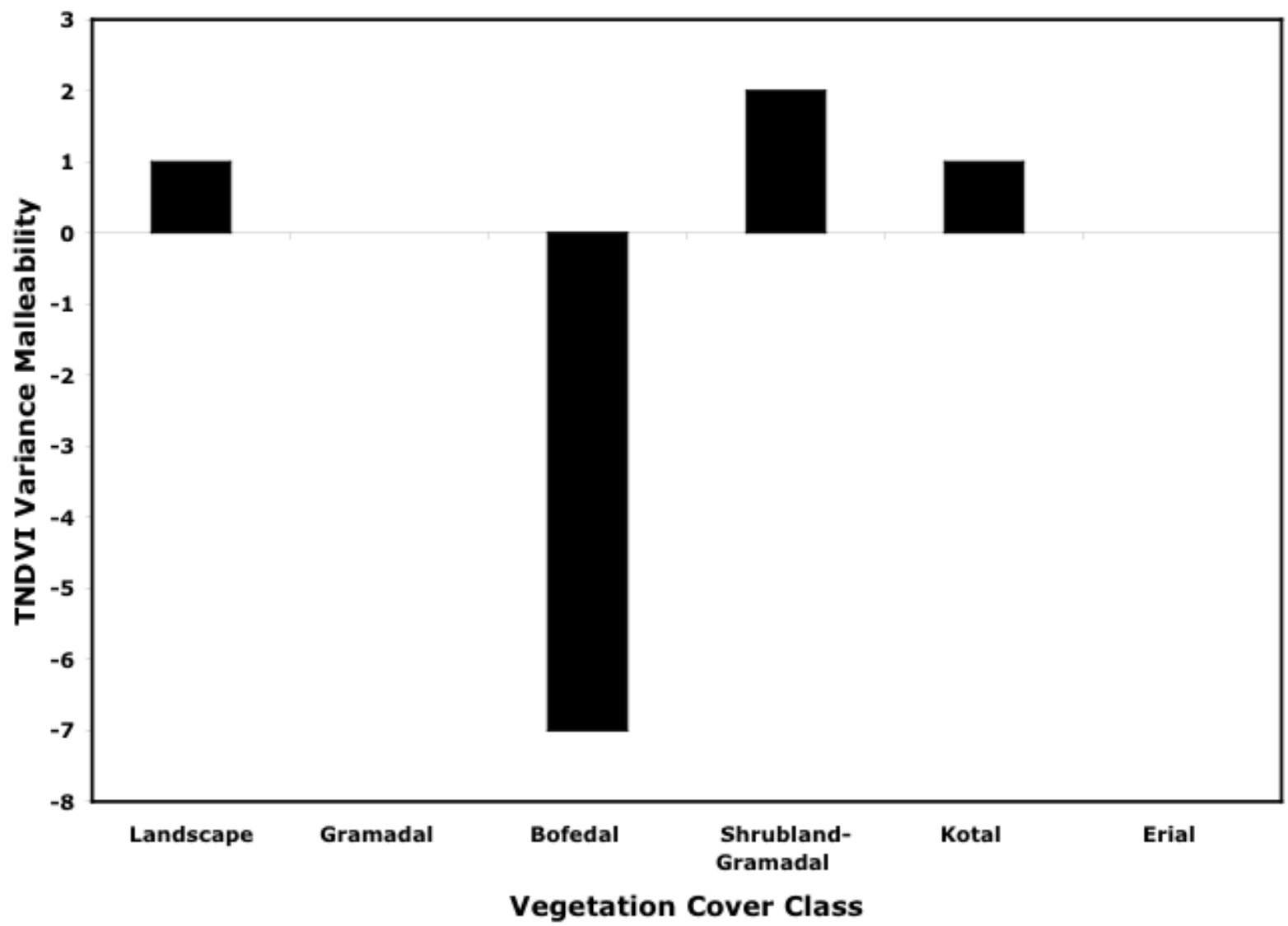

of the 20th century (Glantz 2001). Ellis (1992) hypothesized that because the Altiplano exhibits high climatic variability (coefficient of variation $=$ $31 \%$ ) and has been subject to endemic droughts, a high frequency of frost, and chronic livestock grazing for $>2000 \mathrm{yr}$ (Browman 1974), it should be in a degraded but relatively stable state and resistant to further degradation. However, Painter (1992) has suggested that the Altiplano has lost resilience in the face of multiple droughts and detrimental land- use practices such as overgrazing and that this was responsible for the increased migration to urban centers during the 1982-1984 ENSO. Our meanvariance analysis indicates that, with the exception of bofedal relative to the 1984 drought year, the vegetation index variances were high and the mean response was low. This suggests that during the 1984 ENSO-induced severe drought, the related vegetation response, e.g., vegetation cover, was reduced and bare soil patches were exposed. 
Fig. 6. Mean-variance portraits are quantified in terms of characteristics of ecological resilience, particularly by amplitude. Amplitude is the magnitude of the response of the landscape's transformed normalized difference vegetation index (TNDVI) from reference conditions (in 1972) during or after a disturbance (in 1984). The amplitude for each statistic is calculated by subtracting (A) the mean TNDVIs for 1972 and 1984 and (B) the mean of the TNDVI variances for 1972 and 1984.

A

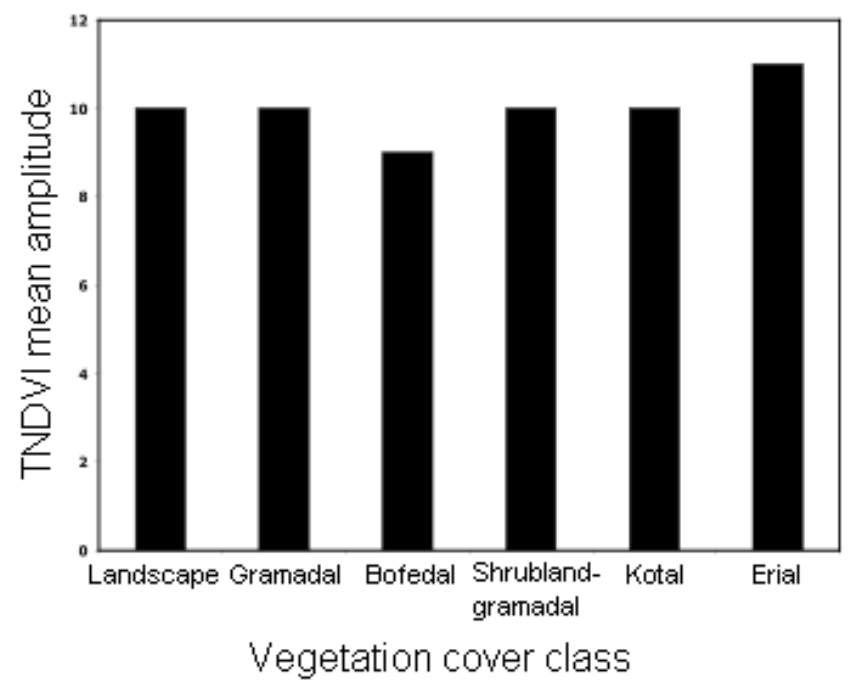

B

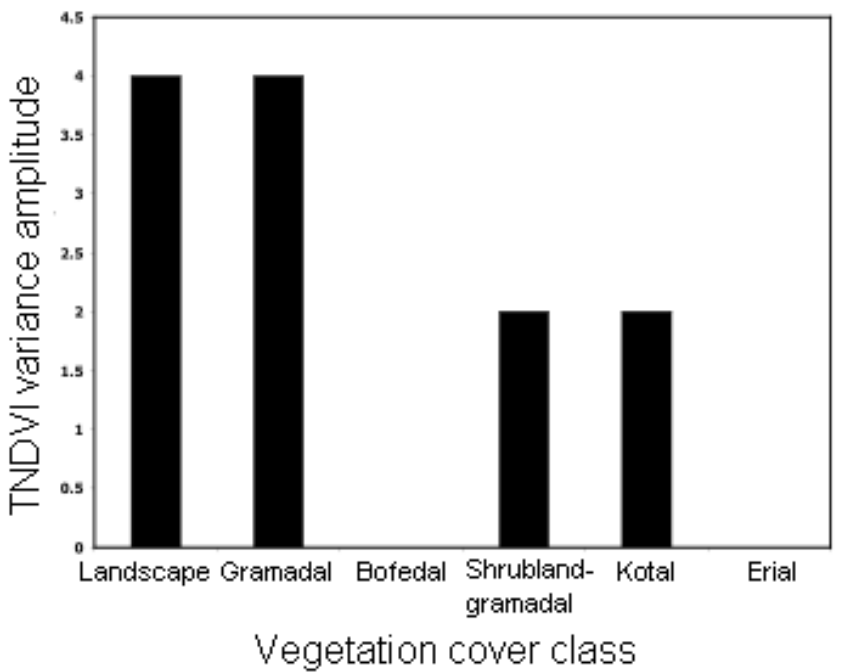

Consequently, there was an increased susceptibility of the landscape to accelerated soil erosion. However, despite the severity of the 1982-1984 ENSO drought event, image and statistical differencing measures of amplitude (the magnitude of the response to disturbance) and malleability (a measure of the degree of recovery) indicated that no thresholds were exceeded, i.e., there did not appear to be a change to another vegetation state because all classes recovered to the reference conditions of 1972. Therefore, these analyses of this limited data set (1972-1987) appear to support Ellis' (1992) hypothesis that the Altiplano is in a degraded but stable state without further decline to another state that can no longer support agropastoral communities, and not Painter's (1992) hypothesis of migration due to current land degradation.
Responses to this article can be read online at:

http://www.ecologyandsociety.org/voll3/iss 1/art33/responses/

\section{Acknowledgments:}

We thank our reviewers and subject editors for their very helpful comments and edits, both the late Walter E. Westman and James E. Ellis for their inspiration and enduring scholarship, and our many colleagues in Bolivia for their logistical support, friendship, and fond memories. This research was funded in part by NSF Biocomplexity Project No. BCS-030846 to Herman H. Shugart Jr. of the University of Virginia and a Faculty Development Grant from the Office of the Vice-Provost for Faculty Affairs, University of Virginia, to R.W-A; in part under the United States Agency for International Development's Small Ruminant Collaborative Research Support Program (USAID-SRCRSP) 
Grant No. DAN/1328G-0046 in cooperation with Instituto Boliviano de Tecnología Agropecuaria to B.E.N.; and in part by the Allen and Alice Stokes Martin Luther King Jr. Minority Graduate Fellowship, Utah State University, to R.W-A.

\section{LITERATURE CITED}

Breshears, D. D., N. S. Cobb, P. M. Rich, K. P. Price, C. D. Allen, R. G. Balice, W. H. Romme, J. H. Kastens, M. L. Floyd, J. Belnap, J. J. Anderson, O. B. Myers, and C. W. Meyer. 2005. Regional vegetation die-off in response to globalchange-type drought. Proceedings of the National Academy of Sciences 102(42):15144-15148.

Brock, W.A., and S. R. Carpenter. 2006. Variance as a leading indicator of regime shift in ecosystem services. Ecology and Society 11(2): 9. [online] URL: http://www.ecologyandsociety.org/vol11/iss2/ art9/.

Browman, D. L. 1974. Pastoral nomadism in the Andes. Current Anthropology 15(2):188-196.

Buttolph, L. P., and D. L. Coppock. 2004. Influence of deferred grazing on vegetation dynamics and livestock productivity in an Andean pastoral system. Journal of Applied Ecology 41 (4):664-674.

Connell, J. H., and W. P. Sousa. 1983. On the evidence needed to judge ecological stability or persistence. American Naturalist 121(6):789-824.

Crist, E. P., and R. C. Cicone. 1984. Comparisons of the dimensionality and features of simulated Landsat-4 MSS and TM data. Remote Sensing of Environment 14(1-3):235-246.

Debinski, D. M., R. E. Van Nimwegen, and M. E. Jakubauskas. 2006. Quantifying relationships between bird and butterfly community shifts and environmental change. Ecological Applications 16 (1):380-393.

Deering, D. W., J. W. Rouse, R. H. Haas, and J. A. Schell. 1975. Measuring forage production of grazing units from Landsat MSS data. Pages 1169-1178 in J. J. Cook, editor. Proceedings of the Tenth International Symposium on Remote Sensing of Environment (Ann Arbor, 1975). Volume 2. Ann Arbor, Michigan, USA.

Dregne, H. E., and N.-T. Chou. 1992. Global desertification dimensions and costs. Pages 249-281 in H. E. Dregne, editor. Degradation and restoration of arid lands. Texas Tech University, Lubbock, Texas, USA. Available online at: $\underline{\mathrm{http}: / / \mathrm{w}}$ ww.ciesin.org/docs/002-186/002-186.html.

Eastman, J. R., and J. E. McKendry. 1991. Change and time series analysis. Explorations in geographic information systems technology. Volume 1. United Nations Institute for Training and Research, Geneva, Switzerland.

Ellis, J. 1992. Recent advances in arid land ecology. Pages 1-14 in C. Valdivia, editor. Sustainable crop livestock systems for the Bolivian highlands. Proceedings of a Small Ruminant Collaborative Research Support Program Workshop (Lubbock, Texas 1991). University of Missouri, Columbia, Missouri, USA.

Ellis, J. E., and D. M. Swift. 1988. Stability of African pastoral ecosystems: alternate paradigms and implications for development. Journal of Range Management 41(6):450-459.

ERDAS Imagine. 1990. Field guide. ERDAS, Atlanta, Georgia, USA.

Friedel, M. H. 1991. Range condition assessment and the concept of thresholds: a viewpoint. Journal of Range Management 44(5):422-426.

Glantz, M. H. 2001. Currents of change: impacts of El Niño and La Niña on climate and society. Second edition. Cambridge University Press, Cambridge, UK.

Goward, S. N., and J. G. Masek. 2001. Landsat30 years and counting. Remote Sensing of Environment 78(1-2):1-2.

Graetz, R. D. 1987. Satellite remote sensing of Australian rangelands. Remote Sensing of Environment 23(2):313-331.

H. John Heinz III Center for Science, Economics, and the Environment, editor. 2002. The state of the nation's ecosystems: measuring the lands, waters, and living resources of the United States. $\mathrm{H}$. John Heinz III Center for Science, Economics, and 
the Environment, Cambridge University Press, Cambridge, UK.

Holmgren, M., and M. Scheffer. 2001. El Niño as a window of opportunity for the restoration of degraded arid ecosystems. Ecosystems 4(2):151-159.

Holmgren, M., M. Scheffer, E. Ezcurra, J. R. Gutiérrez, and G. M. J. Mohren. 2001. El Niño effects on the dynamics of terrestrial ecosystems. Trends in Ecology and Evolution 16(2):89-94.

Holmgren, M., P. Stapp, C. R. Dickman, C. Gracia, S. Graham, J. R. Gutiérrez, C. Hice, F. Jaksic, D. A. Kelt, M. Letnic, M. Lima, B. C. López, P. L. Meserve, W. B. Milstead, G. A. Polis, M. A. Previtali, M. Richter, S. Sabaté, and F. A. Squeo. 2006. A synthesis of ENSO effects on drylands in Australia, North America and South America. Advances in Geosciences 6(1):69-72.

Hudak, A. T., and C. A. Wessman. 1998. Textural analysis of historical aerial photography to characterize woody plant encroachment in South African savanna. Remote Sensing of Environment 66(3):317-330.

Hunt, Jr., E. R., J. H. Everitt, J. C. Ritchie, M. S. Moran, D. T. Booth, G. L. Anderson, P. E. Clark, and M. S. Seyfried. 2003. Applications and research using remote sensing for rangeland management. Photogrammetric Engineering and Remote Sensing 69(6):675-693.

Jensen, J. R. 2005. Introductory digital image processing: a remote sensing perspective. Third edition. Prentice Hall, Upper Saddle River, New Jersey, USA.

Johnson, A. M. 1976. The climate of Peru, Bolivia, and Ecuador. Pages 147-218 in W. Schwerdtfeger, editor. Climates of Central and South America. Elsevier, Amsterdam, The Netherlands.

Lambin, E. F., and A. H. Strahlers. 1994. Changevector analysis in multitemporal space: a tool to detect and categorize land-cover change processes using high temporal-resolution satellite data. Remote Sensing of Environment 48(2):231-244.

Lepers, E., E. F. Lambin, A. C. Janetos, R. DeFries, F. Achard, N. Ramankutty, and R. J. Scholes. 2005. A synthesis of information on rapid land-cover change for the period 1981-2000.
BioScience 55(2):115-124.

Lund, H. G. 2007. Accounting for the world's rangelands. Rangelands 29(1):3-10.

McCorkle, C. M. 1992. Agropastoral systems research in the SR-CRSP Sociology Project. Pages 3-19 in C. M. McCorkle, editor. Plants, animals and people: agropastoral systems research. Westview Press, Boulder, Colorado, USA.

Millennium Ecosystem Assessment. 2005. Dryland systems. Pages 623-662 in Ecosystems and human well-being: current state and trends. Island Press, Washington, D.C., USA. Available online at: http://www.millenniumassessment.org/en/Condition. aspx.

Moris, J. 1988. Failing to cope with drought: the plight of Africa's ex-pastoralists. Development Policy Review 6(3):269-294.

Morse, D. R., J. N. Perry, and R. H. Smith. 2000. A glossary of terms used in nonlinear dynamics. Pages 191-218 in J. N. Perry, R. H. Smith, I. P. Woiwod, and D. R. Morse, editors. Chaos in real data: the analysis of non-linear dynamics from short ecological time series. Kluwer, Dordrecht, The Netherlands.

Nolan, M. 1992. Sociological analysis of small ruminant production systems. Pages 27-45 in J. Barber and M. Keane, editors. Small Ruminant Collaborative Research Support Program annual report. Management Entity, University of California, Davis, California, USA.

Norton, B. E. 1992. Range ecology. Pages 3-20 in J. Barber and M. Keane, editors. Small Ruminant Collaborative Research Support Program annual report. Management Entity, University of California, Davis, California, USA.

Norton, B. E. 1994. Range ecology. Pages 3-20 in S. Johnson, editor. Small Ruminant Collaborative Research Support Program annual report. Management Entity, University of California, Davis, California, USA.

Oldeman, L. R., R. T. A. Hakkeling, and W. G. Sombroek. 1991. World map of the status of humaninduced soil degradation: an explanatory note. Second revised edition. International Soil Reference and Information Centre, Wageningen, 
The Netherlands, and United Nations Environment Programme, Nairobi, Kenya. Available online at: http://www.isric.org/UK/About+ISRIC/Staff+Publications/ ISRIC+reports+and+publications/Working+ Papers+(1989-1999).htm.

O'Neill, R. V. 1976. Ecosystem persistence and heterotrophic regulation. Ecology 57(6):1244-1253.

O'Neill, R. V., A. R. Johnson, and A. W. King. 1989. A hierarchical framework for the analysis of scale. Landscape Ecology 3(3-4):193-205.

Orians, G. H. 1975. Diversity, stability and maturity in natural ecosystems. Pages 139-150 in W. H. van Dobben and R. H. Lowe-McConnell, editors. Unifying concepts in ecology. Dr. W. Junk, The Hague, The Netherlands.

Painter, M. 1992. Changes in highland land use patterns and implications for agropastoral development. Pages 93-121 in C. Valdivia, editor. Sustainable crop livestock systems for the Bolivian highlands. Proceedings of a Small Ruminant Collaborative Research Support Program Workshop (Lubbock, Texas 1991). University of Missouri, Columbia, Missouri, USA.

Perry, Jr., C. R., and L. F. Lautenschlager. 1984. Functional equivalence of spectral vegetation indices. Remote Sensing of Environment 14 (1-3):169-182.

Pickup, G. 1990. Remote sensing of landscape processes. Pages 221-247 in R. J. Hobbs and H. A. Mooney, editors. Remote sensing of biosphere functioning. Springer-Verlag, New York, New York, USA.

Pickup, G., and B. D. Foran. 1987. The use of spectral and spatial variability to monitor cover change on inert landscapes. Remote Sensing of Environment 23(2):361-363.

Prince, S. D. 1991. A model of regional primary production for use with coarse-resolution satellite data. International Journal of Remote Sensing 12 (6):1313-1330.

Quattrochi, D. A., and R. E. Pelletier. 1991. Remote sensing for analysis of landscapes: an introduction. Pages 51-76 in M. G. Turner and R. H. Gardner, editors. Quantitative methods in landscape ecology: the analysis and interpretation of landscape heterogeneity. Springer-Verlag, New York, New York, USA.

Rietkerk, M., S. C. Dekker, P. C. de Ruiter, and J. van de Koppel. 2004. Self-organized patchiness and catastrophic shifts in ecosystems. Science $\mathbf{3 0 5}$ (5692):1926-1929.

Ringrose, S., and W. Matheson. 1987. Spectral assessment of indicators of range degradation in the Botswana hardveld environment. Remote Sensing of Environment 23(2):379-396.

Salm, H., and E. Gehler. 1987. La salinización del suelo en el altiplano central de Bolivia y su influencia sobre la cobertura vegetal. Ecología en Bolivia 10(1):37-48.

Schindler, D. W. 1987. Detecting ecosystem responses to anthropogenic stress. Canadian Journal of Fisheries and Aquatic Sciences 44(S1): s6-s25.

Scoones, I. 1991. Wetlands in drylands: key resources for agricultural and pastoral production in Africa. Ambio 20(8):366-371.

Sellers, P. J. 1985. Canopy reflectance, photosynthesis and transpiration. International Journal of Remote Sensing 6(8):1335-1372.

Singh,A. 1989. Digital change detection techniques using remotely sensed data. International Journal of Remote Sensing 10(6):989-1003.

Suits, G., W. Malila, and T. Weller. 1988 Procedures for using signals from one sensor as substitutes for signals of another. Remote Sensing of Environment 25(3):395-408.

Tueller, P. T. 1989. Remote sensing technology for rangeland management applications. Journal of Range Management 42(6):442-453.

Van Niel, T. G. 1995. Classification of vegetation and analysis of its recent trends at Camp Williams, Utah using remote sensing and geographic information system techniques. Thesis. Utah State University, Logan, Utah, USA. Available online at: http://www.gis.usu.edu/ doug/Grads/TomVanNeil/ TomVanNeil.html.

Washington-Allen, R. A., R. D. Ramsey, B. E. Norton, and N. E. West. 1998. Change detection 
of the effect of severe drought on subsistence agropastoral communities on the Bolivian Altiplano. International Journal of Remote Sensing 19(7):1319-1333.

Washington-Allen, R. A., R. D. Ramsey, and N. E. West. 2004a. Spatiotemporal mapping of the dry season vegetation response of sagebrush steppe. Community Ecology 5(1):69-79.

Washington-Allen, R. A., T. G. Van Niel, R. D. Ramsey, and N. E. West. 2004b. Remote sensingbased piosphere analysis. GIScience and Remote Sensing 41(2): 136-154.

Washington-Allen, R. A., N. E. West, and R. D. Ramsey. 2003. Remote sensing-based dynamical systems analysis of sagebrush steppe vegetation in rangelands. Pages 416-418 in N. Allsopp, A. R. Palmer, S. J. Milton, K. P. Kirkman, G. I. H. Kerley, C. R. Hurt, and C. J. Brown, editors. Proceedings of the VIIth International Rangelands Congress. Durban, South Africa.

Washington-Allen, R. A., N. E. West, R. D. Ramsey, and R. A. Efroymson. 2006. A protocol for retrospective remote sensing-based ecological monitoring of rangelands. Rangeland Ecology and Management 59(1):19-29.

Wessels, K. J., S. D. Prince, M. Carroll, and J. Malherbe. 2007. Relevance of rangeland degradation in semiarid northeastern South Africa to the nonequilbrium theory. Ecological Applications 17(3):815-827.

Wessels, K. J., S. D. Prince, P. E. Frost, and D. van Zyl. 2004. Assessing the effects of humaninduced land degradation in the former homelands of northern South Africa with a $1 \mathrm{~km}$ AVHRR NDVI time-series. Remote Sensing of Environment 91(1): 47-67.

West, N. E. 2003a. Theoretical underpinnings of rangeland monitoring. Arid Land Research and Management 17(4):333-346.

West, N. E. 2003b. History of rangeland monitoring in the U.S.A. Arid Land Research and Management 17(4):495-545.

Westman, W.E.1985. Ecology, impact assessment, and environmental planning. Wiley, New York, New York, USA.
Westman, W. E., and J. F. O'Leary. 1986. Measures of resilience: the response of coastal sage scrub to fire. Vegetatio 65(3):179-189.

Westoby, M., B. Walker, and I. Noy-Meir. 1989. Opportunistic management for rangelands not at equilibrium. Journal of Range Management 42 (4):266-274.

Zimmermann, N. E., R. A. Washington-Allen, R. D. Ramsey, M. E. Schaepman, L. Mathys, B. Koetz, M. Kneubuehler, and T. C. Edwards. 2007. Modern remote sensing for environmental monitoring of landscape states and trajectories. Pages 65-91 in F. Kienast, O. Wildi, and S. Ghosh, editors. A changing world: challenges for landscape research. Springer, Dordrecht, The Netherlands. 